\title{
"A Mushroom Hunt"
}

\section{By RAY PETERSON, R.R.2, Tofield, Alberta}

\section{THIS SUMMER WITH its lavish}

offerings of rain has been a prolific season for the fungus world. Kathryn and I have enjoyed exploring amongst these superstitionveiled plants. We have collected enough specimens to have made dozens of witches brews. Any day, now, we are expecting to remove a mushroom umbrella from over the head of an elf or fairy.

Recently, our "Expedition Mushroom," was quite a successful affair. Our first find was a clump of dainty Glistening Coprinus. These little mushrooms are of a fine, delicate flavor.

From a clump of grass hugging a peplar tree came a larger member of the Coprinus genus. It was a generously proportioned Inky Cap. It had hardly joined its fragile cousins when a very large Fluted-stem Helvella caught our eye. These curiously lobed mushrooms with their fluted pedestals are very intriguing. This is the first year that we have been fortunate enough to find any of them.

Along the edge of a cool, wooded sidehill, the dull orange caps of Bitter Boletus gleamed in heavy splendor. Nearby, under the canopy of a large, drooping diamond willow, lurked the gaudy, splotched heads of a villainous family; Fly Agaric, or Amanita Muscaria. Using my boots bulldozer fashion, I destroyed them.

Another, first, was a colony of roughly scaled, buff-colored mushrooms. They had thick meaty caps, yellow flesh and gills, and were easily recognizable as Honey Agaric. They were included on our supper menu that evening. We found them strongly flavored and rather of fensive of odor.
Embroidering the peaty carpet at the foot of a dense birch grove were hosts of small, heavily frosted fungi. Their pretty grey caps were flushed with a suggestion of purple. A strikingly sharp elevation centered their bell to nearly plane heads. They were entered into the pan reserved for specimens unknown to us. Later we would have an added source of enjoyment in attempting to identify them.

From the same pleasant site we found a number of entirely red mushrooms. A few of them were added to the identification pan, followed by some purplish rosettas of the genus Polyporus.

A few tufts of Golden Clavaria or Golden Coral, too old for table use, were sighted. Then came a pair of dull grey, cup shaped plants and three varieties of little puffballs.

We found only one example of the Ordinary or Common Field Mushroom clan. These mushrooms seem to be scarce in our district this year.

A couple of handsome, reddishpurple samples of Pungent Russula swelled our collection. These small, white-gilled mushrooms certainly live up to the pungent part. A few nibbles of the raw plant is enough to start one's tongue tingling.

Last find of all was a large, very firm puffball that would, and did, provide a goodly number of tasty mushroom steaks.

Along with our sizeable mushroom take, we picked a quart of wild raspberries, and discovered a Dwarf Dogwood that outshone its white-berried relations with an eye-arresting display of deep pastel blue fruit.

This hike, along with similar ones, has given us a wealth of entertainment and heightened our appreciation of Nature's handicrafts.

Here's to more mushrooms. 